\title{
Patients' recommendations for a patient-centred public antiretroviral therapy programme in eThekwini, KwaZulu-Natal
}

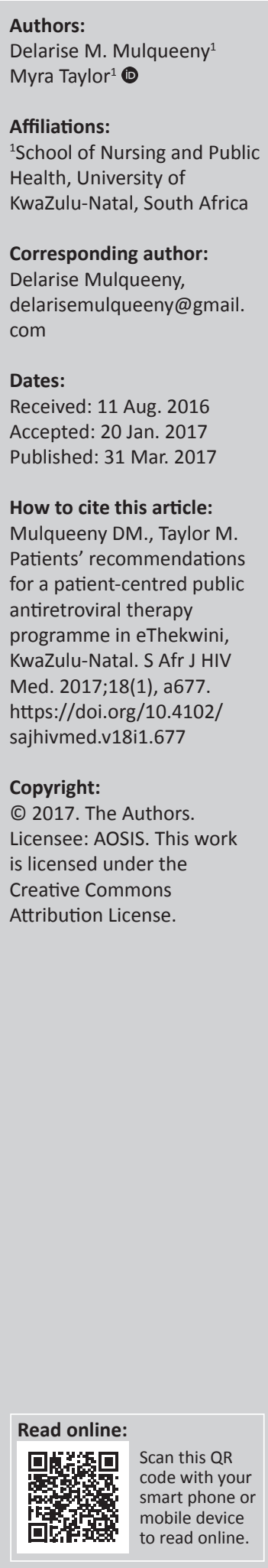

Background: The South African antiretroviral therapy (ART) programme, which is in its second decade of existence, includes many successes and challenges. This study provides patients' recommendations to address the challenges they currently experience at four antiretroviral (ARV) clinics based in urban public hospitals in order to provide a patient-centred service.

Objectives: To use patients' recommendations to develop intervention strategies to improve patients' experiences of the public ART programme.

Method: A three-stage, sequential, mixed-method study was implemented. Stage 1 recruited five patients from the four sites to formulate and test a structured questionnaire prior to data collection. Stage 2 recruited a stratified random sample of 400 patients (100 from each hospital) to complete the administered structured questionnaire. Stage 3 purposively selected 12 patients (three from each of the four sites) to participate in in-depth audio-recorded interviews using an interview schedule.

Results: The 412 patients prioritised six recommendations, which are as follows: waiting areas should be enclosed to protect patients from the elements (rain, sun, lightening, wind and cold); patients should not have to return their files to the main hospital or ARV clinic themselves; stable patients should collect their ARV drugs every three months; pharmacy opening and closing times should be revised to suit patients' needs; HIV-positive patient representatives should be elected at each ARV clinic to address patients' concerns and/or challenges to ensure that the programme could be more patient-centred and ARV clinic operating times should be extended to open later during weekdays and over weekends.

Conclusion: Patients living with HIV have a valuable contribution to make in assessing service delivery and making recommendations to create a patient-centred healthcare environment, which will feasibly increase their adherence to ART.

\section{Introduction}

In 2003, the South African Department of Health initiated a much welcomed antiretroviral therapy (ART) rollout programme for patients. ${ }^{1}$ Subsequent advancements in treatment as well as changes to the eligibility criteria have increased the availability of ART, resulting in people living with HIV (PLHIV) establishing families, living longer and enjoying meaningful employment. ${ }^{2,3}$ PLHIV require comprehensive HIV care, which includes management of opportunistic infections, nutritional deficiencies, antiretroviral (ARV) side effects and co-morbidities as well as assistance with psychosocial, spiritual and socio-economic challenges. ${ }^{4,5}$ This assistance must be ongoing for ARV adherence, to avoid drug resistance and promote retention, which is essential for the success of the ART programme and patients' well-being. ${ }^{6,7}$

The public ART programme is perceived by many as successful. ${ }^{8,9}$ However, it is also affected by challenges, ${ }^{10,11}$ which include all PLHIV receiving quality treatment, adherence, sustaining patients on ART, closing the gap between urban and rural health services and addressing operational problems (strikes, staff and drug shortages, infrastructure challenges, overburdened staff and training and upscaling of staff). ${ }^{12,13,14,15}$ The national HIV Counselling and Testing campaigns $^{16}$ and the South African Health Minister Aaron Motsoaledi's announcement that as from September 2016 all HIV-positive patients could access ART irrespective of their CD4 count is likely to increase the number of patients attending the public ART programme and may further challenge the quality of patient care. ${ }^{17,18,19}$ 


\section{Relevance}

This study reports patients' recommendations based on their experiences, which serve as a patient-driven interventional component, to improve the local public ART programme. Involving patients in assessments of service quality and delivery is a growing trend and becoming a global phenomenon. ${ }^{20}$ Such a study is lacking in South Africa and could be beneficial to policy makers, programme directors and patients and serve as a catalyst to achieve patient-centred care within the current public ART programme and health systems, both locally and nationally.

\section{Objectives}

This study investigated what could be implemented to enable the ART programme to be more patient-centred at four urban public hospitals. The objectives are to describe patients' recommendations to improve the public ART programme, enhance treatment adherence and retention, reduce morbidity and mortality rates and ensure patient-centred care.

\section{Research design and method}

A sequential, mixed-method, multi-site approach was employed to provide reliable and valid results. ${ }^{21}$ Initially, the study utilised structured questionnaires and thereafter face-to-face, in-depth interviews (IDIs) to provide recommendations to improve the quality of care at four ARV clinics, based in hospitals within eThekwini District, KwaZulu-Natal. The reason for the study taking place in this province is that it has the second largest population in South Africa and is at the epicentre of the South African HIV epidemic. . $2,23,24^{2}$

Initially, five experienced and articulate ART patients of both sexes and different ages, a minimum of one from each facility, who did not participate in further data collection, described their experiences and the challenges they encountered and together formulated a total of 41 recommendations to ensure a patient-centred ART programme at their facility. These were included in the questionnaire.

A stratified random sample of patients (400), 100 from each clinic from four public hospitals in the eThekwini District, participated in the administered structured questionnaires. Every fourth patient visiting the clinic was systematically and randomly selected starting with the first patient attending the clinic daily. The quantitative sample comprised 161 men and 239 women of different ages, ethnicity and sexual orientation. Twelve respondents (three from each site) for the IDIs were purposively recruited to achieve gender, race and sexual orientation representation. Six female and six male patients, aged between 18 and 67 years, participated in the interviews, with seven respondents identifying as heterosexual, four as gay and one as bisexual.

All 412 HIV sero-infected patients met the study criteria as they were aged 18 years or older and had accessed the ART programme at one of the four ARV clinics for at least one year or more. Completion of all the questionnaires and interviews took place in and around the outpatient ARV clinics within the hospital grounds.

Informed consent and confidentiality was explained to ensure voluntary participation in the study. No refusals were documented, and all 412 respondents signed informed consent forms prior to the data collection process. This took place from August to November 2015.

All the questionnaires were administered by the principal investigator (PI) and two research assistants who were fully conversant in Zulu, Afrikaans and English. The patients requested the interviews be held in English; however, the trilingual research assistants were also present during the process. No language challenges were reported. The researcher conducted the IDIs with an interview schedule and utilised probes where and when necessary.

\section{Data analysis}

Questionnaires were checked prior to the patients leaving the site, and the data were entered into Epidata software and analysed utilising the Statistical Package for the Social Sciences (SPSS 22) software. The interview transcripts were read several times to ensure a thorough understanding of the information and context. Open-coding techniques were used for the content analysis of each transcript to identify themes and sub-themes based on recurring ideas and concepts. ${ }^{25}$

\section{Reliability and validity}

A sequential, mixed-method design was appropriate to provide reliable, valid results, which Johnson and Onwuegbuzie ${ }^{26}$ describe as important as 'research approaches should be mixed in ways that offer the best opportunities for answering important research questions' (p. 16). To ensure all data were accurately captured, dual recording took place during the interviews. The transcripts were read several times by the researcher and coded using thematic analysis to identify differences and similarities of respondents' answers to ensure the dependability and trustworthiness of the data. Coded questionnaires and interview transcripts ensured anonymity, which provided valid results. The process was continuously discussed and checked by the co-author.

\section{Potential benefits and hazards}

All respondents were allowed to ask questions regarding the questionnaires and interviews prior, during and subsequent to data collection taking place, to ensure all respondents understood the research process. The sensitive nature of the research study dictated that confidentiality and privacy were respected at all times. Patients were offered follow-up sessions with a social worker or counsellor to avoid any psychological or emotional harm. ${ }^{27}$ To respect busy ARV clinics, continuous communication with the clinic 
staff took place. ${ }^{28}$ All completed anonymous questionnaires, electronic records, tape recordings and transcripts were stored in a locked cupboard for the duration of the study and will be destroyed five years after study completion.

\section{Ethical consideration}

The Biomedical Research Ethics Committee (BFC089/15) and the KwaZulu-Natal Department of Health (HRKM158/15) granted ethical clearance, while site clearance was obtained from the four hospital managers prior to the commencement of the study.

\section{Results}

\section{Change, the only constant to ensure patient- centred care}

Five patients from public ARV clinics, together with the PI, formulated 41 recommendations, to ensure that the ART programme at all four hospitals is patient-centred. Patients were required to choose six primary recommendations for the purpose of this study. The quantitative data are presented in Figure 1.

\section{Recommendations from the in-depth interviews}

The six most popular recommendations from the IDIs were similar to those chosen by respondents who answered the questionnaires.

\section{Physical space and infrastructure}

Respondents reported discomfort with open waiting areas as follows:
'They should put an urn outside so we can make ourselves some tea in winter or provide us with sandwiches while we wait outside.' [Participant 12, female, 57 years]

'We have been sitting like this for too long. This waiting area needs to be closed up.' [Participant 7, male, 38 years]

'Government and staff should work with private companies to find money to improve this clinic.' [Participant 9, male, 50 years]

\section{Patient files}

The recommendations below expose an inadequate filing system:

'The filing system must be improved because our files keep getting lost.' [Participant 5, female, 67 years]

'They should invest in a computerised filing system.' [Participant 11 , male, 40 years]

'Hiring qualified staff in the filing department would help.' [Participant 1, female, 62 years]

\section{Antiretroviral drugs collection}

Outsourcing of pharmacies, flexibility of pharmacy operation times and dispensing processes and reduction in the costs of ARV drugs collection are highlighted below:

'It would be so much better if our meds were delivered to our home or work.' [Participant 2, female, 26 years]

'The quicker they outsource the ARV pharmacy the better. It would be much better to collect our medication at private pharmacies such as Dischem or Clicks as we can collect on weekends and after work.' [Participant 5, female, 67 years]

'Surely it would save the staff time, money and irritation if they give us our medication once every three months. I know all the patients would be happy because we would save taxi fare.' [Participant 6, male, 18 years]

\begin{tabular}{|c|c|c|c|c|c|c|}
\hline Option & Hospital 1 & Hospital 2 & Hospital 3 & Hospital 4 & $n=400$ & $\%$ \\
\hline \multicolumn{7}{|c|}{ 1. Waiting areas should be enclosed to protect patients from the elements (rain, sun, lightning, wind and cold) } \\
\hline Yes & 0 & 94 & 98 & 96 & 288 & 72.0 \\
\hline \multicolumn{7}{|c|}{$\begin{array}{l}\text { Hospital } 1 \text { is the only facility where all patients are protected from the elements as the waiting area is within an enclosed space in the main hospital. The other three ARV clinic } \\
\text { are separated from the main hospital and patients have to sit outside the clinic awaiting the opening. Even though the ARV clinic at Hospital } 3 \text { has just undergone a major } \\
\text { refurbishment, patients still have to sit on the clinic veranda, which does not reflect much planning of the refurbishments or the importance of protecting patients. }\end{array}$} \\
\hline \multicolumn{7}{|c|}{ 2. Patients should not have to return their files to the main hospital or ARV clinic themselves } \\
\hline \multicolumn{7}{|c|}{$\begin{array}{l}\text { Hospital } 2 \text { patients return their files to the main hospital after seeing healthcare workers and/or collecting their medication, whilst patients at Hospital } 4 \text { return their files to a } \\
\text { box in the ARV clinic. Patient files at Hospitals } 1 \text { and } 3 \text { are retained at the pharmacy and clerks or cleaners take the files to the filing department and ARV clinic, respectively. }\end{array}$} \\
\hline \multicolumn{7}{|c|}{ 3. Stable patients should collect their ARV drugs every three (3) months } \\
\hline Yes & 55 & 56 & 20 & 47 & 178 & 44.5 \\
\hline \multicolumn{7}{|c|}{$\begin{array}{l}\text { Hospital } 1 \text { only increases the number of ARV drugs collected by patients during the festive season or when a patient has to travel and is unable to make their his/her } \\
\text { appointment date. In such cases, patients provide proof in the form of an air flight or bus ticket. Hospital } 2 \text { provides patients with more than } 1 \text { month's supply of ARV drugs } \\
\text { during the festive season, because of travel, examinations or if there is a directive from Head Office. Hospitals } 3 \text { and } 4 \text { were flexible in their frequency of dispensing ARV drugs. } \\
\text { However, because of stock-outs of certain ARV drugs in 2015, some patients had to collect monthly. }\end{array}$} \\
\hline Yes & 1 & 38 & 86 & 4 & 129 & 32.3 \\
\hline \multicolumn{7}{|c|}{$\begin{array}{l}\text { The pharmacy opening times for Hospitals } 1,2 \text { and } 4 \text { were consistent, whereas the opening times at Hospital } 3 \text { were erratic. On the days that the PI was at Hospital } 3 \text {, the } \\
\text { pharmacy did not open before 8:30, and she observed it once opening at 8:50. However, closing times were consistent at all four hospitals. }\end{array}$} \\
\hline \multicolumn{7}{|c|}{ 5. HIV-positive patient representatives should be elected at each ARV clinic to address patients' concerns/challenges } \\
\hline Yes & 19 & 19 & 41 & 36 & 115 & 28.8 \\
\hline \multicolumn{7}{|c|}{$\begin{array}{l}\text { There is no patient committee or patient representative that represents patients at any of the clinics. The PI observed nine respondents from Hospital } 4 \text { complete the } \\
\text { Department of Health's 'Make Me Look Like A Hospital Project Client Satisfaction Survey'. However, between August and November } 2015 \text {, the PI only observed the survey bein } \\
\text { completed once, with only } 20 \text { surveys being handed out and less than } 20 \text { patients completed the questionnaire on that day. }\end{array}$} \\
\hline \multicolumn{7}{|c|}{ 6. ARV clinic operating times should be extended to open later during weekdays and over weekends } \\
\hline Yes & 41 & 25 & 24 & 22 & 112 & 28.0 \\
\hline
\end{tabular}

ARV, antiretroviral; $\mathrm{PI}$, principal investigator.

FIGURE 1: Patient recommendations. 


\section{Patient representation and satisfaction}

Respondents' need for patient involvement, engagement and representation are expressed below:

'I feel we should have a representative, representing us. We should do anonymous forms and hand it in outside this clinic.' [Participant 1, female, 62 years]

'If we had one of our own representing us I think the service would improve for us.' [Participant 2, female, 26 years]

'Patients should be involved because patients tell other patients the truth, not staff. They need our input so they should employ us as patient therapists because we are the experts.' [Participant 3 , male, 46 years]

'A representative should sit in on hospital meetings so our problems are put forward.' [Participant 6 , male, 18 years]

'We need to be involved in this programme so that service improves all the time.' [Participant 8 , female, 29 years]

'Patients must be represented so we know and understand our rights.' [Participant 9, male, 50 years]

'I don't think a patient rep will make a difference, we are just HIV patients.' [Participant 10, male, 46 years]

'Even though we receive good service from the clinic staff I think it is important for a representative to discuss the pharmacy story. They should hire patients as role-models.' [Participant 7, male, 38 years]

These responses emphasise patients' need for a trustworthy, engaging and empowering environment and a programme that promotes patients' self-worth and rights. All these recommendations promote and embody patient-centred care.

\section{Pharmacy operational times}

The responses below articulate patients recommending outsourcing of the ARV pharmacies and revision of operational times:

'They should close this pharmacy and let us go to private chemists to collect.' [Participant 4, male, 35 years]

'If they don't want to change the weekday times they should let us collect on the weekend or from private chemists.' [Participant 8 , female, 29 years]

'The pharmacy is an area of concern at this clinic. If they can sort it out, then this would be a clinic that other medical staff could learn a thing or two from the staff at this clinic.' [Participant 7, male, 38 years]

The latter response highlights the respondents' satisfaction with service delivery and even suggests learning opportunities for other ARV clinic staff. This latter respondent accesses treatment at Hospital 3, which has inconsistent pharmacy opening times.

\section{Antiretroviral clinic operational times}

Extension of clinic operational times and inclusion of signage to suit patients' needs are recommendations provided below:

'We should be able to attend a clinic after hours. [Participant 4 , female, 35 years]
'Signs should be put up of how long it's going to take us in this clinic.' [Participant 5, female, 67 years]

'Weekends are the solution as most working people are off work.' [Participant 10, male, 46 years]

'All clinics should open at 7 o'clock and close at $5 \mathrm{pm}$ so that we can be seen before or after work.' [Participant 11, male, 40 years]

Worth noting was that the majority of the patients arrived at the hospital between 4:00 and 7:00, which entailed them leaving their homes very early to meet their scheduled 7:00 appointments. Respondents required ARV clinics operational times to be extended to open earlier, close later and include weekends.

\section{Discussion}

Patient-centred care places patients at the centre of their healthcare journey. ${ }^{29}$ Hence, patients recommending improvements and changes to ensure a patient-centred ARV clinic is both empowering and inclusive to the patient healthcare dynamic. ${ }^{30}$ The six most popular recommendations focus on improvement to the physical space and infrastructure, patients' files, ARV drug collection frequency, patient representation and satisfaction, pharmacy operational times and the ARV clinic operational times.

\section{Physical space and infrastructure}

The majority of the questionnaire respondents (72\%) recommended enclosed waiting areas, which concurs with an evaluation of the ART programme in KwaZulu-Natal, South Africa, which highlighted the 'mismatch between supply and demand' ${ }^{31}$ A comfortable safe environment where patients are not concerned about the elements and being seen by others should be a priority for all sites as is the case with Hospital $1 .^{32}$

\section{Patient files}

The results concur with the findings of an assessment of public ARV clinics conducted between June and November 2009 and another study conducted at a Johannesburg clinic, which highlighted challenging filing systems as new files were opened and such challenges lead to loss to followup. ${ }^{33,34}$ An electronic or improved filing system could improve patient turnaround time and lessen the opportunity for files being lost. The study highlighted the inconsistency and variability of services and processes between sites, which requires further interrogation.

\section{Antiretroviral drug collection and pharmacy operational times}

ARV stock-outs, transportation costs and lengthy waiting times are challenges that patients are confronted with when collecting their ARV drug and other chronic medication. The study results concur with a study conducted at a public hospital, which concluded that ARV drugs are provided free of charge; however, the cost of attaining them (transport, 
time off work) is high and could affect adherence..$^{35,36}$ The introduction of the Central Chronic Medicine Dispensing and Distribution Programme (CCMDD) is an attempt at alleviating such challenges. This programme allows patients to collect their chronic medication from designated pharmacies and healthcare facilities. These facilities operate after hours and on weekends and would be meaningful and cost-effective for patients on ARV drugs, as they would be able to access their medication nearer to their homes and/or workplace at times that are convenient for them. ${ }^{37}$ However, the data collection process took place in 2015 and this intervention had not been implemented at the four study sites. During 2016 some sites have introduced the programme. Hence a follow-up study on the impact of the CCMDD programme might yield different results.

\section{Patient representation and satisfaction}

Respondents viewed themselves as 'patient therapists', 'rolemodels' and 'experts' who should be involved and/or employed at ARV clinics to assist other patients and play an active role in improving systems and processes to enhance patient care. ${ }^{38}$ These findings concur with a study conducted at 18 Sub-Saharan health facilities to assess the degree of patient involvement at HIV care hospitals, which concluded that patient involvement was a necessity towards improving service delivery. ${ }^{34}$ A Malawian study also highlighted the benefits of involving PLHIV in treatment programmes. ${ }^{39}$ Our study results also highlighted patients' internalised and healthcare workers' stigma and disrespect, which contradicts the findings of Kieft et al. 2014. ${ }^{40}$

\section{Antiretroviral clinic operational times}

Most patients were in the ARV clinic for between one and two hours from the time they entered to the time they exited. This timeframe did not include collecting their ARV drugs as three ARV pharmacies are separate from the ARV clinics. The refurbishments at Hospital 2's ARV clinic included a pharmacy inside the clinic, which was unique and saved patients' time. The pharmacy and clinic operational times have been documented as challenges to patients in other studies. ${ }^{41,42}$ Hence, patients' recommendations of flexible and extended operational hours, which include earlier and later closing times and weekends, could be beneficial. The rollout of the Central Chronic Medicine Dispensing (CCMD) and implementation of flexible, extended hours could improve patients' experiences.

Some recommendations can be implemented at the hospital level, whereas others require provincial and national intervention in terms of budgetary and human capital resources. These would promote patient-centred care through strengthened patient-provider relationships; improved and extended pharmacy and operational times; warm, nurturing clinics; continuous improvement; qualified, patient-friendly and respectful staff; empowering and engaging systems; reciprocal communication; improved outsourcing services; patient representation and satisfaction; destigmatised clinical environments; and updated filing systems and processes. The recommendations further provide opportunities for staff to learn best practices from each other and other clinics to improve their systems and processes.

However, inasmuch as these six recommendations did not prioritise waiting times, waiting areas, staff attitudes, patient-provider relationships, staff training, stock-outs and financial assistance, the other recommendations did and are discussed in subsequent papers. The patients' six recommendations and the 35 that are included in Appendix 1 would result in a patient-centred clinic that patients approve of and signify an ideal ARV clinic.

\section{Limitations of the study}

The study was conducted at four hospitals within eThekwini district; therefore, more studies at other hospitals and Primary Health Care $(\mathrm{PCH})$ facilities could yield further recommendations for improvement of the current ART programme in KwaZulu-Natal.

\section{Recommendations}

Staff perceptions and experiences of the public ART programme as well as their recommendations for patientcentred ARV clinics could be explored in future studies.

\section{Conclusion}

As patients are the cornerstone of the South African ART programme, it is important and relevant to understand their needs 12 years after the rollout of the public ART programme. The findings are concerning for sites within a large metro; however, room for change and improvements to the programme were highlighted. The study also emphasised that the patients were prepared to assist in improving the status quo by offering recommendations that could be feasibly implemented to improve the current ART programme. The results presented patients' willingness to participate as 'patient therapists', 'role-models' and 'expert' patients. This study concurs with other relevant studies regarding patient experiences of the public ART programme and healthcare system but goes further to provide recommendations for improvement.

\section{Acknowledgements}

The authors would like to thank all the patients for participating in this study.

\section{Competing interests}

The authors declare that they have no financial or personal relationships, which may have inappropriately influenced this article.

\section{Authors' contributions}

D.M.M. was a PhD candidate and M.T. the supervisor while writing this article. 


\section{References}

1. Nyasulu JCY, Muchiri E, Mazwi S, Ratshefola M. NIMART rollout to primary healthcare facilities increases access to antiretrovirals in Johannesburg: An interrupted time series analysis. S Afr Med J. 2013;103(4):232-236. https://doi. org/10.7196/SAMJ.6380

2. Green K, Dix O, Mwangi-Powell F, Horne C, Luyirika E. Where's the care in the postART era? Afr Health. 2012:19-21.

3. Hoa DM. Antiretroviral therapy (ART) adherence among people living with HIV/ AIDS (PLHIV) in the North of Vietnam: A multi-method approach [PhD thesis]. AIDS (PLHIV) in the North of Vietnam: A multi-method approach [PhD thesis]. Brisbane, Australia: School of Public Health, Faculty of Health and Institute of
Health and Biomedical Innovation, Queensland University of Technology; 2011.

4. Ndou TV, Maputle SM, Risenga PR. HIV-positive patients' perceptions of care received at a selected antiretroviral therapy clinic in Vhembe district, South Africa.
Afr J Prim Health Care Fam Med. 2016;8(2):a926. https://doi.org/10/10.4102/ phcfm.v8i2.926

5. van Dyk AC. HIV/AIDS care and counselling: A multidisciplinary approach. 4th ed. Cape Town: Pearson Education; 2012.

6. Liau A, Crepaz N, Lyles $\mathrm{CM}$, et al. Interventions to promote linkage to and utilization of HIV medical care among HIV diagnosed persons: A qualitative systematic review, 1996-2011. AIDS Behav. 2013;17(6):1941-1962. https://doi. org/10.1007/s10461-013-0435-y

7. Horstmann E, Brown J, Islam F, Buck J, Agins BD. Retaining HIV-infected patient in care: Where are we? Where do we go from here? Clin Infect Dis. 2010;50(5): 752-761. https://doi.org/10.1086/649933

8. Moorhouse M. Closer to zero: Reflections on ten years of ART rollout. S Afr Med J. 2014;15(1):9. https://doi.org/10.7196/sajhivmed.1030

9. Johnson LF. Access to antiretroviral treatment in South Africa, 2004-2011. South Afr J HIV Med. 2012;13(1):1-8.

10. Surender R. The drivers of universal health care in South Africa: The role of ideas, institutions and actors. Working Paper 2014-19. Prepared for the UNRISD project on Towards Universal Social Security in Emerging Economies: Process, Institutions on Towards Universal Social Security in Emerging Economies: Process, Institutions and Actors. Geneva, Switzer

11. Orner P, Cooper D, Myer L, Zweigenthal V, Bekker L, Moodley J. Clients' perspective on HIV/AIDS care and treatment and reproductive health services in South Africa. AIDSCare.2008;20(10):1217-1223. https://doi.org/10.1080/09540120701867008

12. Kranzer K, Govindasamy D, Ford N, Johnston V, Lawn SD. Quantifying and addressing losses along the continuum of care for people living with HIV infection in sub-Saharan Africa: A systematic review. J Int AIDS Soc. 2012;15(2):17383. https://doi.org/10.7448/IAS.15.2.17383

13. Wouters E, Van Rensburg HCJ, Van Loon F, Meulemans H. State of the ART programme: Clinical effectiveness and physical and emotional quality-of-life improvements in the Free State Province, South Africa. AIDS Care. 2009;21(11): 1401-1411. https://doi.org/10.1080/09540120902884034

14. Alcorn K. Public service strike disrupting HIV care in South Africa [homepage on the Internet]. 2007a [cited 2014 Jun 1]. Available from: http://www.aidsmap. com/en/news/68D9B80FC4BC-4A73-93FB-2C2F1C3A146C.asp

15. Evans D. Ten years on ART - Where to now? S Afr Med J. 2013;103(4):229-231. https://doi.org/10.7196/SAMJ.6835

16. Miller $C M$, Ketlhapile $M$, Rybasack-Smith $H$, Rosen $S$. Why are antiretroviral treatment patients lost to follow-up? A qualitative study from South Africa. Trop Med Int Health. 2010;15(Suppl 1):48-54. https://doi.org/10.1111/j. 1365-3156.2010.02514.x

17. Health24 [homepage on the Internet]. 2016 [cited 2016 Jun 22]. Available from: http://www.health24.com/Medical/HIV-AIDS/Management-of-HIV-AIDS/arvsnow-for-anyone-with-hiv-says-minister-20160510

18. Timesalive [homepage on the Internet]. 2016 [cited 2016 Jun 22]. Available from http://www.timeslive.co.za/local/2016/05/10/Government-updates-HIV-policyto-allow-ARV-treatment-for-all-South-Africans

19. Govindsamy D, Ford N, Kranzer K. Risk factors, barriers and facilitators for linkage to antiretroviral therapy care: A systematic review. AIDS. 2012;26(16):2059-2067. https://doi.org/10.1097/QAD.0b013e3283578b9b

20. Church K, Lewin S. Delivering integrated HIV services: Time for a client-centred approach to meet the sexual and reproductive health needs of people living with HIV. AIDS. 2010;24(23):189-193.
21. Subedi D. Explanatory sequential mixed method design as the third research community of knowledge claim. Am J Educ Res. 2016:4(7):570-577. https://doi. org/10.12691/education-4-7-10

22. Creswell JW, Plano Clark V. Designing and conducting mixed methods research. Thousand Oaks, CA: Sage; 2007.

23. Statistics South Africa. [cited 2014 Jun 03]. Available from: http://www.statssa. gov.za/publications/P0302/P03022014.pdf

24. Ramjee G, Moonsamy S, Abbai NS, Wand H. Individual and population level impact of key HIV risk factors on HIV incidence rates in Durban, South Africa. PLoS One. 2016;11(4):e0153969. https://doi.org/10.1371/journal.pone.0153969

25. Gale NK, Heath G, Cameron E, Rashid S, Redwood S. Using the framework method for the analysis of qualitative data in multi-disciplinary health research. BMC Med Res Methodol. 2013;13:117. https://doi.org/10.1186/1471-2288-13-117

26. Johnson RB, Onwuegbuzie AJ. Mixed methods research: A research paradigm whose time has come. Educational Researcher. 2004; 33(7):14-26.

27. Molyneux C, Goudge J, Russell S, Chuma J, Gumede T, Gilson L. Conducting healthrelated social science research in low income settings: Ethical dilemmas faced in Kenya and South Africa. J Int Dev. 2009;21(2):309-326. https://doi.org/10.1002/ jid.1548

28. Engelbrecht MC, Bester CL, van Den Berg H, van Rensburg HCJ. A study of predictors and levels of burnout: The case of professional nurses in primary health care facilities in the Free State. S Afr J Econ. 2008;76(Suppl 1):15-27. https://doi. org/10.1111/j.1813-6982.2008.00164.x

29. Scholl I, Zill JM, Hërter M, Dirmaier J. An integrative model of patient-centeredness A systematic review and concept analysis. PLoS One. 2014;9(9):1-9. https://doi. org/10.1371/journal.pone.0107828

30. Vahdat S, Hamzehgardeshi L, Hessam S, Hamzehgardeshi Z. Patient involvement in health care decision making: A review. Iran Red Crescent Med J. 2014;16(1):e12454 https://doi.org/10.5812/ircmj.12454

31. Vella V, Govender T, Scelo D, et al. Evaluation of antiretroviral therapy against HIV/ AIDS in KwaZulu-Natal, South Africa [homepage on the Internet]. Pietermaritzburg: KwaZulu Natal Department of Health; 2008 [cited 2 May 2014]. Available from: http://www.kznhealth.gov.za/italian/arv.pdf

32. Huisman ERCM, Morales E, van Hoof J, Kort HSM. Healing environment: A review of the impact of physical environmental factors on users. Build Environ. 2012;58:70-80. https://doi.org/10.1016/j.buildenv.2012.06.016

33. Kinkel HF, Adelekan AM, Marcus TS, Wolvaardt G. Assessment of service quality of public antiretroviral treatment (ART) clinics in South Africa: A cross-sectional
study. BMC Health Serv Res. 2012;12(228):1-12. https://doi.org/10.1186/1472study. BMC Heal

34. Shumba CS, Atukunda R, Memiah P. Patient-centred quality care: An assessment of patient involvement. Int J Med Public Health. 2013;3(2):77-80. https://doi. org/10.4103/2230-8598.115159

35. Rosen S, Ketlhapile M, Sanne I, DeSilva MB. Cost to patients of obtaining treatment for HIV/AIDS in South Africa. S Afr Med J. 2007;97(7):524-529.

36. Maskew M, MacPhail P, Menezes C, Rubel D. Lost to follow-up: Contributing factors and challenges in South African patients on antiretroviral therapy. $S$ Afr Med J. 2007;97(9):853-857.

37. Health Systems Trust [homepage on the Internet]. 2016 [cited 2016 Sep 11]. Available from: http://www.hst.org.za/projects/central-chronic-medicinedispensing-and-distribution-programme-ccmddcmddp

38. Mwai GW, Mburu G, Torpey K, Frost P, Ford N, Seeley J. Role and outcomes of community health workers in HIV care in sub-Saharan Africa: A systematic review. $\mathrm{J}$ Int AIDS Soc. 2013;16(1):18586. https://doi.org/10.7448/IAS.16.1.18586

39. Tenthani L, Cataldo F, Chan AK, Bedell R, Matiniuk ALC, van Lettow M. Involving expert patients in antiretroviral treatment provision in a tertiary referral hospital
HIV clinic in Malawi. BMC Health Serv Res. 2012;12:140. https://doi.org/10. 1186/1472-6963-12-140

40. Kieft R, De Brouwer B, Francke A, Delnoij D. How nurses and their work environment affect patient experiences of the quality care: A qualitative study. BMC Health Serv Res. 2014;14:249. https://doi.org/10.1186/1472-6963-14-249

41. Mathibe MD, Hendricks SH, Bergh A. Clinician perceptions and patient experiences of antiretroviral treatment integration in primary health care clinics, Tshwane, South Africa. Curationis. 2015;38(1). https://doi.org/10.4102/curationis.v38i1.1489

42. Peltzer K. Patient experiences and health system responsiveness in South Africa. BMC Health Serv Res. 2009;9:117. https://doi.org/10.1186/1472-6963-9-117 


\section{Appendix 1}

TABLE 1-A1: Other recommendations.

Recommendation

Food and refreshments should be served while patients are waiting to be attended to

Pill counts should be stopped when patients are deemed stable by the doctor

Registration and admin processes should be streamlined and made patient-friendly

Opening times for cashiers and ARV clinics should be regulated to ensure that they open

at the same time every day

Patients should have their blood pressure, sugar levels and weight checked at all ARV

clinics

ARV patients should only register at the ARV clinic

Turnaround time for routine and emergency blood results should be improved so patients do not wait so long

Patients should be allowed to make and change their appointments over the telephone

It should be mandatory that health talks are held daily and are conducted in isizulu and English at this ARV clinic

IsiZulu and English HIV support groups should be formed at all ARV clinics

Filing systems and processes

Barcoded patient cards and files should be implemented so patients swipe instead of waiting in queues

Filing systems should be improved to avoid files being lost

Separate ARV patient files should be kept at the ARV clinic to avoid being lost in the main hospital filing department

\section{Staff, supervision and training}

Supervisors should conduct ad hoc checks to ensure staff are doing their job and treating patients professionally

Dieticians should be based in all ARV clinics to advise patients about their dietary requirements

Staff meetings should take place in the afternoons

A minimum of two fully qualified doctors should be permanently on duty at this ARV clinic to ensure swift service

Staff should not be allowed to use their personal cell phones and tablets during working hours

Social workers should be stationed at each ARV clinic to address patients' concerns and challenges

Vacant positions should be filled as soon as possible to ensure clinics are adequately staffed

Regular training should take place so that staff are up-to-date about HIV treatment, policies and guidelines

Staff should receive regular training and updates about the LGBTI community and diversity

Staff supervisors should ensure that staff commence work on time and adhere to the stipulated tea and lunch times

Automated clock card systems should be placed at each ARV clinic to monitor staff attendance

Staff lunch and tea times should be staggered to ensure there are always sufficient staff on duty

Communication and signage

IsiZulu and English legible signs and flow charts should be put up

Isizulu and English legible signs should be put up to and lunch

$\begin{array}{lllllll}\text { Option } & \text { Hospital } 1 & \text { Hospital } 2 & \text { Hospital } 3 & \text { Hospital } 4 & n=400 & \%\end{array}$

$\begin{array}{lcccccc}\text { Yes } & 11 & 15 & 36 & 28 & 90 & 22.5 \\ \text { Yes } & 0 & 1 & 0 & 53 & 54 & 13.5 \\ \text { Yes } & 39 & 7 & 0 & 1 & 47 & 11.8 \\ \text { Yes } & 30 & 0 & 1 & 5 & 36 & 9.0 \\ \text { Yes } & 32 & 0 & 0 & 0 & 32 & 8.0 \\ \text { Yes } & 11 & 18 & 0 & 0 & 29 & 7.3 \\ \text { Yes } & 5 & 3 & 18 & 0 & 26 & 6.5 \\ \text { Yes } & 17 & 8 & 0 & 0 & 25 & 6.3 \\ \text { Yes } & 2 & 7 & 2 & 0 & 11 & 2.8 \\ \text { Yes } & 2 & 2 & 7 & 0 & 11 & 2.8\end{array}$

26

Yes

Yes

27

10

29

11

88

22.0

Yes

Yes

Yes

Yes

Yes

Yes

0

\section{Pharmacy}

ARV scripts should be saved in the pharmacy's computer system to avoid patients having Yes to fetch and carry files

Pharmacy operational and waiting time signs should be put up outside the pharmacy so Yes that patients are aware of them

\section{Patient representation and satisfaction}

Patients should form part of ARV clinic committees to ensure they are represented on Yes matters that affect patients

Patients should complete anonymous questionnaires after each visit regarding the service Yes they received

\section{Outsourcing and networking}

Antiretroviral treatment programmes should be outsourced to private doctors/hospitals Yes to reduce the strain on the public health system

Private pharmacies such as Dischem, Clicks and Sparksport should be allowed to dispense Yes ARV drugs

Private laboratories should be used for routine blood tests and blood results should be Yes linked to the ARV clinic

ARV drugs should be delivered to patient's homes

Yes

Yes
Yes

S

20

0

60

$$
22
$$

$$
20
$$

24

20

1

$21 \quad 5.3$

ARV, antiretroviral; LGBTI, Lesbian, gay, bisexual, transgender, and intersex.

Note: For inclusivity, the other 35 recommendations have been divided into themes. 